\title{
REVIEWING THE IMPACT OF ADVANCED CONTROL ROOM TECHNOLOGY"
}

Cheryl A. Wilhelmsen, David I. Gertman, Lee T. Ostrom, William R. Nelson, William J, Galyearty $\operatorname{Jim} C$. Byers

Human Factors Research Unit

Idaho National Engineering Laboratory

EGG-M-91550

EG\&S Idaho, Inc.

P.O. Box 1625

Idaho Falls, ID $83415-2405$

DE92 018032

\begin{abstract}
Progress to date on assessing the nature of the expected changes in human performance and risk associated with the introduction of digital control, instrumentation, and display systems is presented. Expected changes include the shift toward more supervisory tasks, development of intervention strategies, and reallocation of function between humar and machine. Results are reported in terms of the scope of new technology, human performance issues, and crews experience with digital control systems in a variety of industries including petrochernical and aerospace. Plans to conduct a limited Probabilistic Risk Assessment/Human Reliability Assessment (PRA/HRA) comparison between a conventional NUREG-1150 series plant and that same plant retrofit with distributed control and advanced instrumentation and display are also presented. Changes needed to supplement existing HRA modeling methods and quantification techniques are discussed.
\end{abstract}

\section{INTRODUCTION}

The introduction of digital control systems and advanced display systems as either retrofit to existing control rooms or as part of advanced reactor design brings with it a unique set of challenges for the risk. analyst. Equipment configurations for these systems are evolving and the underlying failure rates for human errot probabilities and hardware component failures have yet to be determined. The introduction of digital control systems (DCS) and advanced display systems, e.g., Cathode Ray Tube-based (CRT), integrited displays, involves three changes, all of which have a direct impact upon risk. The changes are: (1) the configuration of the plant will change physically; (2) the allocation of functions, between humans and hardware will change; and (3) there will be different failure modes and associated failure rates for hardware, software, and human actions and decisions.

Projections as to the expected change in risk are difficult to make for the following reasons: failure rates for the most recent generation of haroware are not well established or researched

\footnotetext{
a. The views and conclusions in this puper are those of the autbors and do not necessanly reflect the polscies of the U. S. Nuclear Regulatory Commission. This work was funded in pert by the U.S. Nuclear Regulatory Commission, Otfice of Nuclear Regulatory Researib, uader DOE Contract No. DE-AC07-761D01570. Neither the United Stute Government not any agency thereof, nor any of their employees, makes any warranty, expressed or implied, or ussumes sny legal liability or responsibility for the accuracy, complaceness, or usefulness of any unformation, appararus, produce or process disclosed or represents that its use would bot infringe privately owned nighus.
}

either in the nuclear industry or other complex industries; the role of operator and crew functioning with new configurations of equipment, with various degrees of automation has been partially researched but failure rate information has not yet been developed; and although improved methods for estimating software reliability are emerging, well defined rates for software intensive, highly digital systems are not yet established. Some non-US nuclear industries specify an unavailability design requirement of $1.0 \times 10^{3}$ for shutdown systems. [1] The unavailability of a function may be improved when nonredundant code is incorporated. (Redundant code negates gains made by diversity). Existing methods of human reliability analysis (HRA) performed to support probabilistic safety analysis: model and identify human-machine, and human-human failure modes; employ quantification approaches; and make use of, or generate estimated data. [2] All existing contemporary methods were developed from a model of the analog control room and a traditional allocation of tasks and subsequent presentation of plant parameter information to control room crews. All three components of contemporary HRA must be modified if they are to be used to estimate risk associated with advanced Nuclear Power Plant (NPP) design.

A number of national and international plans for the introduction of DCS for control, instrumentation, and information display exist. For purposes of this project, the scope of the relevant technologies which have been identified for our HRA comparison between conventional and advanced US designed plants inciude:

- digital control of auxiliary feedwater system

- digital control of reactor protoction systems

- automatic calibracion

- automatic self-test features (for sensors and transmitters)

- advanced instrumentation and operator information presentation systems (color CRTs, trending information, across a varinty of sensors and systems, etc.)

- hybrid contul (digital control for some aspects only)

- automatic alarm logging and report generation capability

- automated presentation of procedures

Features which are either now available for use in US and foreign NPPs, which will soon be available for use, or are proposed for future use in NPPs and which have been identified during the course of this project include those mentioned above as well as:

- computer-assisted fuel reloading at power (Canadian designed, CANDU reactors)

- automated procedures generation systems (advanced Toshiba PODLA[3] design, and Halden Reactor Project, Integrated Surveillance and Control System (ISACs)[4] program)

- early fault detection programs

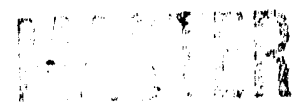


- automated venting (proposed Advanced Boiler Water Reactor (ABWR) design)

- core follow programs

- star-up and shut-down activities (proposed A-PODIA design. Darlington-A shutdowri)

- self detecting and correcting software

- design for error tolerance

- advanced systems such as the French SPIN system which can perform calculations related to deviations in power or Denucleate Boiling (DNB) and initiate reactor trip on that basis

- cotal digital control (Darlington, CANDU, Mitsubishi design, and proposed DOE - Westinghouse Savannah River Corporation's New Production Reactor (NPR) design)

- interface with expert systems

- technical specification and validation systems

- automated control of water purification systems (a non safety grade system)

- Speech recognition (advanced, 5th generation PODIA design)

Additionally, we have assumed, for purposes of future analysis that operation: will retum to manual control if the automatics fail. We further assume that provision for reliability has been made in terms of diversity (independent pathways) and redundancy. The exact level for each will be defined during the event sequence analysis phase of this project. In general, this project does not deal with software spexification and design.

Work in 1991 idenlified the range of uncerainty associated with changes in activities and decisions representative of the implementation of DCS. This was accomplished in two tasks. The first entailed defining the scope of DCS terhnology likely to be present in the near term. The second step was accomplished by review of US NPP experience with DCS. This was accomplished through literature review, on-site evaluation in the case of a Department of Energy (DOE) facility, and a petrochemical facility, and interviews with operator licensee examiners familiar with US NPPs where DCS had been installed. Experience with these systems has received mixed results. The availability of data and information has increased, but operating crews in plants with mixed technology see no justification for reductions in staffing levels, nor do they feel any decrease in their workload. They do, however, report significant gains in the amount and accuracy of trend information available to them and in many instances report an increase in their diagnostic capability and accuracy.

Next, current HRA modeling methods and quantification methods were examined to see if they were sufficient 10 support the analysis of the incorporation of DCS/advanced reactor design at US NPPS. HRA modeling methods such as functional event trees and HRA event trees are amenable, with slight modification, to representing a shift to more cognitive, supervisory activities associated with DCS. Existing HRA data sources such as Technique for Human Error Rate Prediction (THERP) data tables or time reliability correlation approaches fail to encompass appropriate failure rate information associated with sophisticated activities likely to be part of the tasks performed in a DCS-based NPP control room. Other sources, such as the Nuclear Computerized Library for Assessing Reactor Reliability (NUCLARR) [5] data bank, fail to epresent these data to any large extent because NUCLARR data comes primarily from PRA sources. PRA has, until the present time, excluded the more cognitively based errors of commission.
Efforts conducted so far in 1992 include, using the methods identified in 1991 to conduct a limited PRA/HRA comparison. Failure rates and the core melt frequeicy (CMF) for the conventional NUREG-1150 plant will be compared to those rates for that same plani once advanced design (DCS) features have been retrofit. As part of that analysis process, the INEL hopes to develop Human Frror Probability (HEP) data tables to supplement THERP. The tables will reflect ertor rates for actions and decisions in NPPs where DCS and advanced instrumentation and displays have been retrofit or where an advanced design has been implemented. A, n event sequence will be selected where the DCS will be called upon for purposes of supportung either crew detextion, diagnosis, or intervention. The plant configuration as well as the failure rates for human actions and decisions will be factored into the INEL PRA analysis. As part of this effort, the INEL will also model and calculate the impact of software and hardware reliability in DCS systems upon core melt frequency (CMF).

\section{SURVEY RESULTS}

During the course of this study the number of identified HRA issues related to the introduntion of digital technology and advanced display systems numbered over thirty. Ten issues or concerns which may compromise crew performance with these systems (and shange the corresponding generic failure rates associated with crew performance in traditional systems) have been identified. The most pressing issues are presented below:

1. Crews may not have a clear picture of what the plant is doing when systems are partially disabled.

2. Crews may not have a sense of what the automatics are doing particularly during mode changes and may, as a result, be illprepared to intervene. (For example, crews may not have availahle to them representations of the algorithms in use or where in the execution of that 1 gorithm the plant happens to be). Therefore, quick changes from automaric mode to manual mode may be unsettling.[6]

3. The operational logic employed by the automatics may only partially be understood by crew members. [6]

4. Data entry may be time consuming, and error prone. Recovery, however, will be possible.

5. Software version control may be a problem.

6. Manual practice with routine lasks that promote a sense of system "feel" for the operator and provide operator confidence may be eliminated. [7] Higher failure rates for other wasks could result.

7. Communication and coordination activities will increase and these types of errors may tend to dominate HRA failure rate estimates.

8. More operator time will be spent in what is commonly referred to as "knowledge-based activities realm." Rather than thinking in procedural terms, crews will think of applying strategies to meet objectives. This is done by applying the appropriate resources, and making selections among various success paths. Most HRA methods, other than expert judgment methods, deal poorly with supervisory- or decision-based tasks. 
9. The importance of crews being computer literate as a parameter influencing their performance with advanced systems is an under reponed phenomenon which could either increase or decrease failure rates.

10. The availability of on-line procedures has the potential of enhancing operator performance, particularly if the system provides for: the logic flow, lists the procedural step(s), and allows for multiple procedures to be opened. [4]

The experience with DCS, which is presented below, was gathered by a survey, structured interviews, and a review of national and international sources. The experience is rather wide ranging; 4 US NPPs, 1 petrochemical plant, 1 DOE reactor facility, Ontario Hydro training operations, and Hiuman Factors personnel. Operator licensee exarniners were used to supply US NPP information. Data cited from the National Aeronautic and Syace Administration Agency (NASA), Federal Aviation Administration (FAA), and foreign utilities and industry were gathered from literature survey sources. Fourteen factors with majer significance were determined from experience with DCS and are outlined below:

1. Plant availability has been increased after the implementation of DCS. (Point LePreau[8], Darlington-A, Canada) (US NPP. Plant C).

2. Crew cognitive as opposed to physical work load has increased after DCS implementation. (Ontario Hydro Responses).

3. Computer literacy for crews is more impertant than previously recognized (DOE experience with crews in an advanced. DCS facility).

4. Recovery from inplit errors was more rapid from using a DCS interface than wi th a conventicnal interface, i.e., feedback is rapid, apparent, and changes in related variables are both faster and easier to spot (Petrochemical Plant. survey findings).

5. It was possible for crews to control more variables, to much greater tolerances, with digital, as opposed to analog controllers and displays (Petrochemical Plant survey findings, Plant D experience).

6. Crews stated a greater trust in digital as opposed to analog output (Petrochemical Plant survey findings).

7. Operating experience with DCS is that you have a better plant overview and view of the plant at a glance, (i.e., situation awareness), (Survey of US NPPs-Plant C, Plant D).

8. Trends can be called up quickly and the representation is beiter than strip charts. Digital trending is superior over analog trending or purely numerical digital displays (Survey of US NPPs, Plant C \& Plant D).

9. Lower level of staffing is not allowed as a result of DCS implementation (Survey of US NPPs, all respondents).

10. Early fault detextion, sperator support systems, and automated procedur's wer e perceived as advantageous by operator crews (Halden simulator experience). [9]
11. Some degree of reluctance exists in terms of tuming over control of the plant to DCS for high consequence sequences, (e.g., auto synchronization of breakers, Diesel Generators (DGs), or turtines, or auto-rod control); (Survey of US NPPS, Plant D).

12. Ability to pull up system mimics which are key to particular plant evolution is a positive feature of DCS system implementation. (Survey of US NPPs, Plant D).

13. DCS implementation has provided for a greater breadth and depth of information related to the secondary side at NPPs. This in turn, has assisted in problem recognition and trouble shooting activities. (Survey of US NPPs, Plant D).

14. Calibration and adjustment are required on a less frequent basis than with analog systems. (Surrey of US NPPS, Plant B).

\section{CONCLUSIONS}

It is possible, as well as advisable, to proceed with determining the impact of the effects of digital control and advanced display systems on crew performance and concomitant changes in risk for retrofitted or advanced design NPPs. Enough qualitative data exists in the nuclear industry and in sister industries where some of the same issues and types of equipment apply to assist in identifyir.g expected changes in crew performance and in error rates. Our findings to date indicate that the best approach is to:

- Postulate a DCS implementation and identify associated changes in hardware configuration and plant systems line-ups.

- Employ functional event trees and modified HRA event trees to reveal aspects of crew cognition and the potential for human error which could result.

- Make use of NASA research in order to establish a cognative taxonomy. Make use of the NASA model for humar, sentered automation (adapted from Billings 1991). [10]

- Create HEP estimates for operations conducted in DCS and advanced display system environments either through modification of existing failure rate information data bases or through the use of rigorous engineering judgment/estimation exercises.

- Determine failure rate estimates or the process for estimation of new hardware such as digital transmitters and digital sensors and related DCS software.

- Perform PRA analysis for sclect cutsets and determine core melt frequency.

- Conduct a sensitivity analysis comparing the findings, and produce HEP estimates to suppiement existing NUCLARR and NUREG/CR-1273 data tables.

\section{ACKNOWLEDGEMENTS}

The authors wish to thank Carl E. Johnson, Jr., of the U.S. Nuclear Regulatory Commission, RES, DSR for his support and contributions as Program Manager. 
[1] Requirements for Shutdown Systems for CANDU Nuclear Power Plants, A Regulatory Policy Statement, Atomic Energy Control Board, R.8, 1991

[2] Galyean, W.J., and D.I. Gertman. Assessment of ISLOCA Risk-Methodology and Application to a Babcock and Wilcox Nuclear Power Plant, NUREG/CR-5604, Vo. 1-3, Washington, DC. Vol 1. pp. 9-8, 1992.

[3] Tai, I., Naito, N. and Makino, M., Advanced Control Complex for BWR Nuclear Power Plant, Procedings of the Human Factors Society, 35 th Annual Meeting, San Francisco, CA, pp 643-649, 1991.

[4] K. Haugset, O. Berg, N.T. Fordestrommen, J. Kvalem, and W.R. Nelson, "ISACS-1, the Prototype of an Advanced Control Room." IAEA International Symposium on Balancing Automation and Human Action in Nuclear Power Plants, Munich, West Germany, July 9-13, 1990.

[5] Reece. W.J., and Gertman D.I., NUCLARR: A Workstation Software Package to Support Risk Assessment, Reliability Enginering \& System Safety, 1992 (in press).

[6] Sarter, N.B. and Woods, D.D., Pilot Interaction with Cockpit Automation, CSEL Report The Ohio State University, Columbus, OH, 199!

[7] O'Hara, J.M., Advanced Human System Interface Design Review Guidelines, NUREG/CR-4545, Washington, DC., 1991.

[8] Taylor, Gregg M., Point Lepreau: One of the world's best, Nuclear News, March 1992.

[9] Kennedy, W.G., Lessons Leamed in Process Control at the Halden Reactor Project, NUREG-1361, U.S. Nuclear Regulatory Commission, Washington, DC., 1989.

[10] Billings, C.E., Human-Centered Aircraft Automation Philosophy, NASA-Ames Kesearch Center, Moffett Field, CA, 1991.

\section{DISCLAIMER}

\footnotetext{
This report was prepared as an account of work sponsored by an agency of the United States Government. Neither the United States Government nor any agency thereof, nor any of their employtes, makes any wartanty, express or implied, or assumes any legal liability or responsibility for the accuracy, completeness, or usefulness of any information, apparatus, product, or process disclosed, or represents that its use would not infringe privately owned rights. Refermanufacturer or othecific commercial product, process, or service by trade name, trademark, manufacturer. or otherwise does not necessarily constitute or imply its endorsement, recommendation, of favoring by the United States Government or any agency thereof. The views and opinions of authors expressed herein do not necessarily state or reflect thase of the United States Government or any agency thereof.
} 

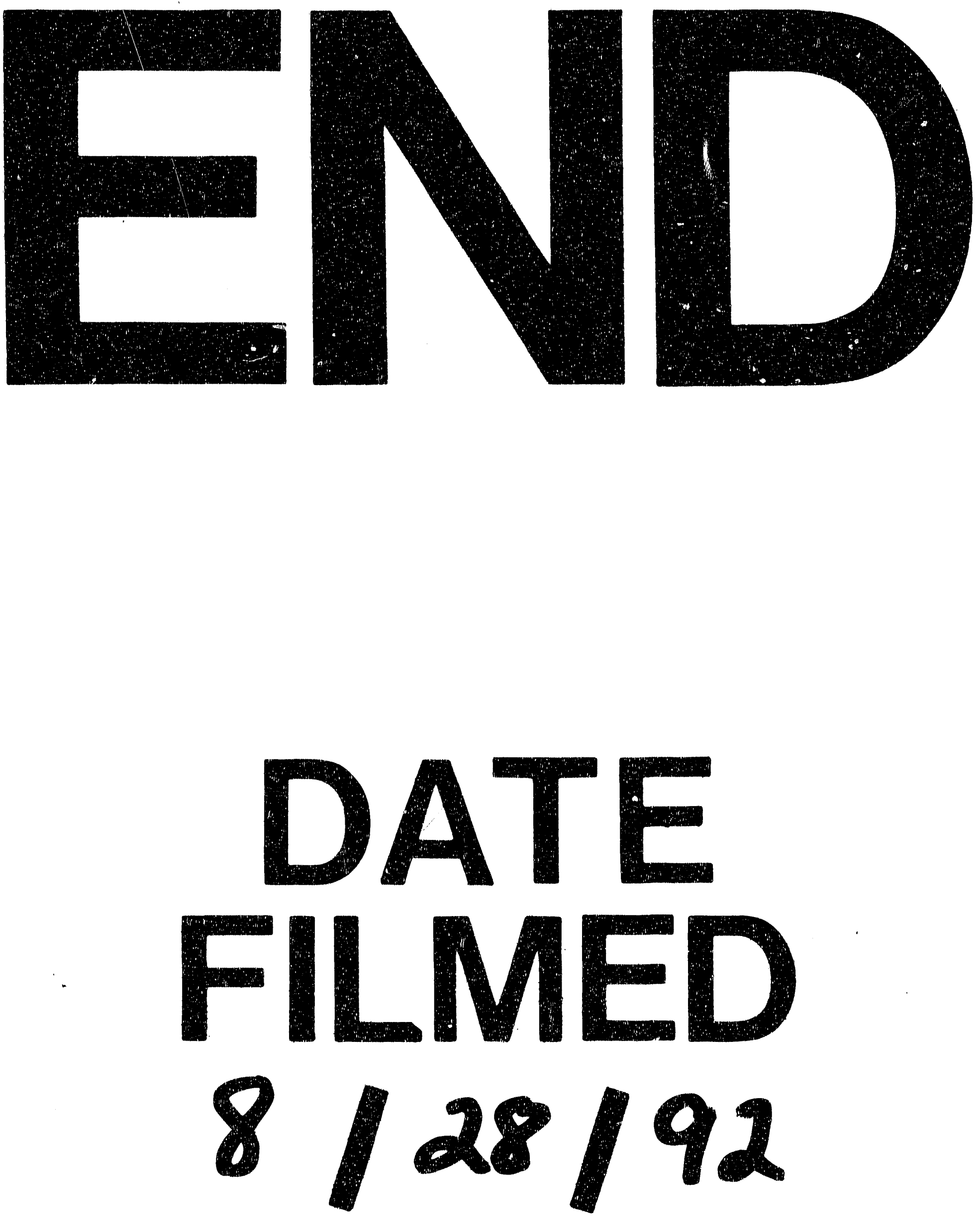
n 